\title{
Las enfermedades raras en Portugal desde la perspectiva de medicina interna
}

\author{
Status of Rare Diseases from the perspective \\ of Internal Medicine in Portugal
}

\author{
Maria Teresa Cardoso \\ President of Portuguese Society of Metabolic Disorders 2018-2020 \\ Head of the Adult Metabolic Unit of University Hospital Centre São João Porto, Portuguese Reference Center for Metabolic Disorders \\ Head of Internal Medicine AM Unit, Department of Internal Medicine. University Hospital Centre S. João, Porto, Portugal
}

In Portugal, it is estimated that there are about six hundred to eight hundred thousand people with rare diseases. About $80 \%$ are of genetic origin. Usually chronic and debilitating, they have a strong family, social and health system impact. Rare diseases usually have a late diagnosis, in about 25\% of patients the diagnosis is made 5 to 13 years after the first symptoms, according to the international literature'.

Inherited metabolic diseases (IMD) are a group of rare genetic disorders resulting from an enzyme defect and/or transport proteins in metabolic pathways affecting proteins, fat, carbohydrate metabolism or impaired organelle function. More than 1000 disorder are identified ${ }^{2}$. Although they are individually rare, their collective prevalence is estimated today at greater than 1:800 individuals $^{3}$. Improvements in screening programs, disease awareness and diagnostic tests have led to increasing numbers of patient diagnosis and to the detection of milder or late-onset forms that present in adulthood ${ }^{4}$.

In Portugal we have forty years of Newborn screening. It started with PKU and congenital hypothyroidism in 1979 and expanded to 24 inherited metabolic disorders in 2004. The Cystic Fibrosis screening was integrated in 2018, making a total of 26 pathologies screened. The National Plan for Early Diagnosis (PNDP) created in 1979 has a national coverage rate close to $100 \%$. Since 1993 over 99\% of newborns has been screened. The average time to start treatment was 10 days. These are important indicators, it is a highly efficient program at European level ${ }^{5}$.

Since the beginning of the Program, more than 2,132 patients have been diagnosed. If we consider the 26 diseases screened in our country, we find a global incidence of 1: 1,122 newborns. Although the 24 inherited metabolic diseases screened are rare diseases, as a whole have an incidence of 1: 2296, near 1: 2,000 people, according to Orphanet in Europe. Analyzing the incidence at birth of screened IMD, the disease most frequently identified is MCAD deficiency (the most common disorder of fatty acid oxidation), followed by Phenylketonuria (aminoacidopathy), which is in accordance with the epidemiological data available in other countries ${ }^{5}$.

The National Institute of Health Ricardo Jorge where screening is done, carried out biochemical/enzymatic and molecular confirmation of the pathologies screened in the identified cases. This Laboratory Unit is also dedicated to the investigation and diagnosis, at national level, of many Rare Diseases namely Inherited Metabolic Diseases. Currently, it provides Next Generation Sequencing (NGS) and genetic panels for the molecular diagnosis of inherited diseases of metabolism.

The expansion of the newborn screening plan in 2004 required the creation of Treatment Centers. Thus, in 2005, the definition of Inborn Errors of Metabolism was published in the Republic Diary, the definition of dietary products for therapeutic purposes, the conditions of 100\% co-payment as well as the Treatment Centers responsible for their prescription. Ten treatment Centers for Inherited Metabolic Disorders were created three in Porto, two in Lisbon, two in Coimbra and three in Madeira and the Açores ${ }^{6}$.

In 2008 the National Plan for Rare Diseases was approved and Inherited Metabolic Diseases were considered priority intervention area.

The process of recognition by the Ministry of Health of Reference Centers in IMD began in 2014, with the Treatment Centers evolving to five Reference Centers officially recognized in 2016 after application, two in Porto, two in Lisbon, one in Coimbra, currently integrated into the European Reference Network MetaBERN?.

Talking about evolution, nowadays $50 \%$ of patients with inherited metabolic diseases are adults, according to the Scientific report from Board annual meeting 2018 MetabERN and the percentage of patients diagnosed as adults represents more than $40 \%$, an expanding population ${ }^{8}$. Several factors 
contribute to these numbers: the expansion of newborn screening increases the diagnosis in affected parents, improved metabolic and genetic diagnostic detect milder adult forms of disease and increasing survival to adulthood ${ }^{9}$. This progress in IMD made them pass from a limited predominantly pediatric group of intractable and often fatal diseases, to a large group of diseases with chronic evolution reaching adulthood with increasing treatment solutions.

In Portugal the first Metabolic Unit started in 1975 in Lisbon, followed by Porto in 1984 and Coimbra in 1995. Initially Pediatric Units, the introduction of metabolic adult physicians mainly specialists in Internal Medicine, started in 2003 in Porto followed by the remaining centers. The introduction of an Organized Transition consultation came later, although it started since the adult team joined the centers in 2003 (graphic 1).

With the creation of Reference Centers in 2016, it was necessary to establish the criteria for referral of patients. Clinical norms were approved by DGS (Direção Geral de Saúde) about Diagnostic Approach and Referral Criteria for Inherited Metabolic Disorders in Pediatric Age and in Adult. This norm states indications for diagnostic evaluation according the presentation symptoms at the different ages, the familiar history, the newborn screening, indicates ways of referral, to where they should be referred, ways of articulation at different levels of health care, clinical information needed, action plan (flow chart) and responsibilities ${ }^{10}$.

To Ensure that in emergency situations, healthcare professionals have access to the clinical information of the person with a rare disease, a Card of the Person with Rare Disease (CPDR) implementation program was started in 2014.

It is a digital card developed by DGS in an accessible format at different levels of health care to improve continuity of care and favor quick referral for reference center. The request is of the exclusive competence of the attending physician at public or private hospitals through the Electronic Health Record Platform with access in the citizen site of the National Health Service Portal ${ }^{11}$.

To provides the rare patient with all information about genetic tests, reference centers, orphan drugs, access to education and social support the DGS published The Support Information for Persons with Rare Disease $2019^{12}$.

All these actions are integrated into the new strategy, The Integrated Strategy for Rare Diseases 2015-2020 which replaced the National Program for rare Diseases 2008 because its scope of action went beyond the health sector. The new strategy is now based on intersectoral and interinstitutional cooperation and implemented by an Inter-ministerial Commission'.

The main objectives are to ensure that in an integrated manner, the rebalancing of priorities in the global approach to rare diseases bring together

Figure 1. Inherited metabolic disorders (IMD) in Portugal.

\section{REFERENCE CENTERS}

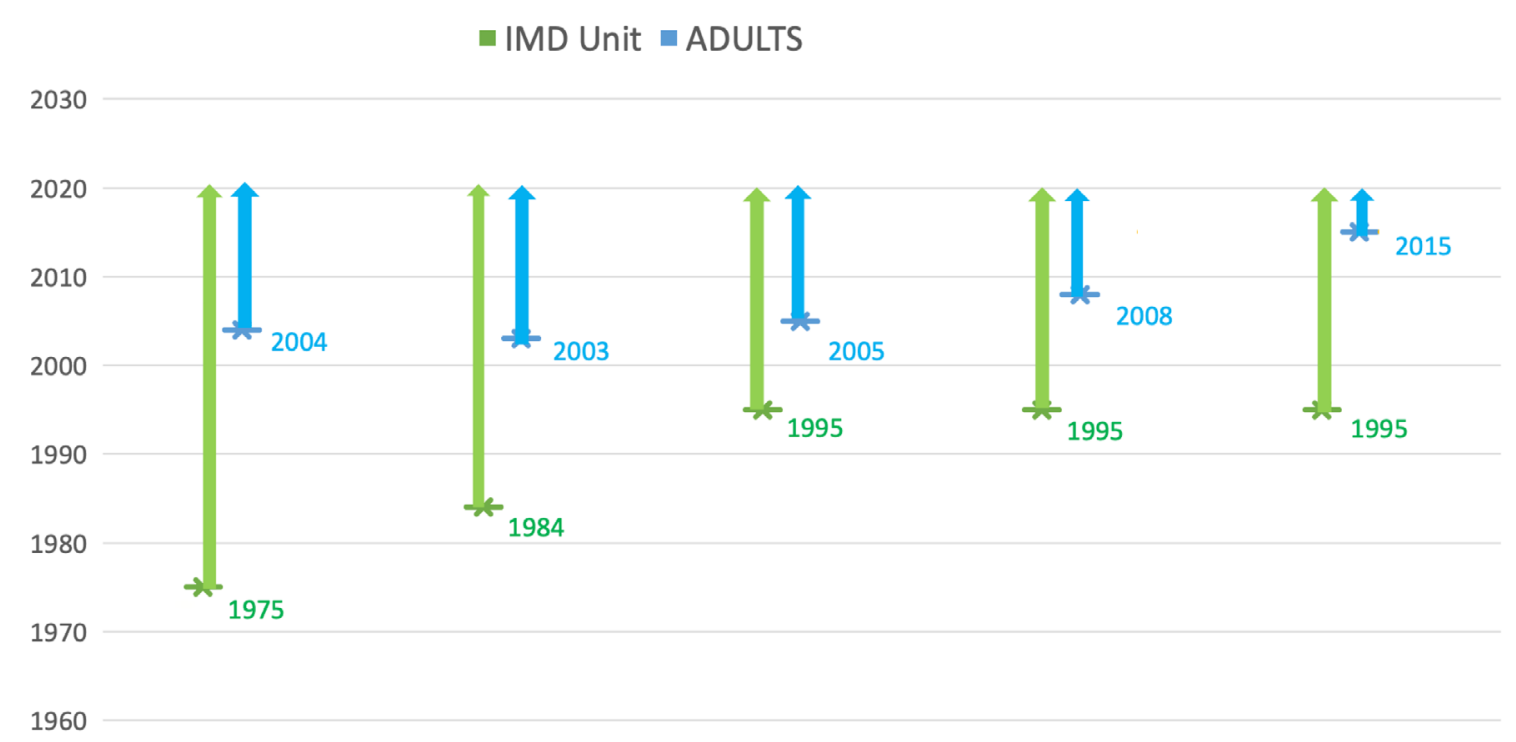


the contribution of skills and resources from all relevant sectors.

The Integrated Strategy for Rare Diseases is supported by the following concepts: The delay in the diagnosis of rare diseases means that timely intervention opportunities may be lost. Rare diseases may be identified in all medical specialties. It is necessary to be aware of the possibility of diagnosing a rare disease in a patient. It is important to recognize and to refer the patient to highly specialized centers. Reference Centers with multidisciplinary teams with advanced scientific and clinical competences allow patients to benefit from new treatments, knowledge and research. It is important that all medical and multi-professional specialties have access to knowledge on rare diseases".

This strategy is based on care coordination, epidemiological information, basic, clinical and translational research, national and international cooperation and social integration to obtain the earliest diagnosis and treatment access for rare diseases. Inborn errors of metabolism integrated into this large group of rare diseases, are currently one of the hottest topics in medicine. The number of therapies approved for IMD for the past two decades has grown exponentially. ERT has greatly improved the morbidity and mortality associated with many lysosomal storage disorders. Some IMD can now be expected to have a good prognosis with appropriate management and early diagnosis is a prerequisite for effective treatment.

The Orphan drugs used to treat these rare diseases, are so rare, that the cost of developing and placing on the market will not be recovered by the expected sales. The accessibility of a certain orphan medicinal product in a certain country depends on the strategy of the laboratory and the decision taken by national health authorities concerning reimbursement. It is mandatory to highlight the importance of convergence of stakeholders in the orphan drug industry to discuss and interact with government, hospitals, clinicians, pharmaceuticals, biopharmaceuticals, non-profit organizations and orphan drug developers. Increase the knowledge on IMD, improve communication and cross-border collaboration between the various research centers, the institutions and the patients continue to be a priority.

In Portugal spending on orphan drugs during 2019 increased by 35 million euros, about 13\% of National Health System hospital drug expenses. Lysosomal Diseases (DLS) was one of the areas with the greatest spending increase. It has been observed an increase in orphan drugs costs in DLS, by $31 \%^{13}$.

Lysosomal disease prevalence in newborns in Portugal is 25 / 100,000 live births. In the last few years, several enzyme substitution and substrate reduction therapies have been developed. They are very costly and reimbursed by Portuguese $\mathrm{Na}$ tional Health System ${ }^{14}$.

The need to regulate the administration of therapies led to the creation in 1993, (with the beginning of the enzymatic treatment of Gaucher disease) of a Coordinating Committee for The Treatment of Lysosomal Diseases.

It is an interinstitutional commission with the participation of The National Institute of Health Ricardo Jorge (INSA), the Reference Centers in DHM e DLS, the Central Administration of the Portuguese Health System (ACSS), the Directorate-General for Health (DGS) and the National Authority for Medicines and Health Products (INFARMED).

Its activity consists essentially in the definition of criteria for the initiating and suspension of treatment, monitoring of clinical evolution and the need for dose adjustment or treatment change, registration of the number of patients treated, by hospital, by pathology and therapy and elaboration of evaluation and follow-up protocols, as well as circuits of requests and patient information sheets ${ }^{14}$.

According the last Portuguese annual report the number of patients with lysosomal disorders undergoing treatment was 276 , with an $8 \%$ increase in the number of lysosomal patients treated in the last year ${ }^{14}$.

IMDs emerge as a challenging group of diseases in the adult health care system. There are increasing number of adult patients, demonstrating the need for metabolic adult physicians aware of these diseases and their high phenotype variability.

Existing adult metabolic specialists (AMS) come from many different backgrounds, mainly from Internal Medicine specialty. Continuous care for adult IMD patients with uninterrupted good metabolic treatment throughout childhood and adolescence is a new and challenging reality. Especially a coordinated transition in a specialized outpatient clinic in a cooperation of the pediatrics and internal medicine departments is very important.

In order to meet this growing demand, programs of formal training in adult IMD are needed. Formal training and postgraduate education is not available in the majority of countries ${ }^{6}$. In Portugal, there is a post-graduate training Ciclo de Estudos especiais in Hereditary Metabolic Diseases approved by the Minister of Health in 2007 with a 2 years du- 
ration aimed especially at Pediatricians and Internists. It is organized by the Pediatrics Department of the Reference Center for Hereditary Diseases of Metabolism at CHUS João and by the Faculty of Medicine of Porto University. The Portuguese Society of Metabolic Disorders has an important role in stimulating and support research and training in this field providing access to several annual grants that include an important Research Support Grant, several Clinical Internships for adult physicians and pediatricians and ShortTerm Scholarships.

Diagnosis of inborn errors of metabolism has undergone a major evolution. The Newborn screening originally intended for early-onset treatable disorders evolves into expanded screening programs with the use of tandem mass spectrometry increasing the number of diseases that can be detected. The era of biochemistry evolves into the era of omics, genomics and metabolomics. The diagnosis of late-onset or adult variants, particularly for the lysosomal storage disorders and of variants of uncertain significance that are potentially pathogenic raises several questions. There are still open questions about who will need treatment, when it should start, which affected individuals will need pre-symptomatic treatment, what its cost-benefit and who may never become symptomatic ${ }^{15}$.

Treatment of inborn errors of metabolism also undergone a great evolution, in most of the 20th century was largely aimed at reducing abnormal metabolites, in the 21st century have become aimed at more directly correcting the underlying metabolic defect through chaperonins, enzyme replacement therapy, therapeutic mRNA, gene therapy, microbiome manipulation, organ and cell transplantation.

A larger group of diseases with increasing treatment solutions, with chronic evolution reaching to adulthood take the place of a limited group of intractable and often fatal diseases, predominantly pediatric.

Now we have greater organizational capacity, new diagnostic and therapeutic strategies with parallel cost expansion and budget cuts. How to deal with the expanding costs of Inherited metabolic diseases, with the expanding diagnostic capacity and the expanding news therapies for expanding rare patients?

The perception that all this evolution has already brought benefits to knowledge and indirectly to the entire world population, is an important though when we consider costs.

\section{BIBLIOGRAFÍA}

1. Direção Geral de Saúde. Integrated Strategy for Rare Diseases 2015-2020, DGS 27th of February 2015 Disponible en: http://www.orpha.net/national/data/PTPT/www/uploads/INTEGRATED-STRATEGY-FOR-RARE-DISEASES.pdf

2. Ferreira CR, van Karnebeek CDM, Vockley J, Blau N. A proposed nosology of inborn errors of metabolism. Genet Med. 2018;21(1):102-6.

3. Mak CM, Lee HC, Chan AY, Lam CW. Inborn errors of metabolism and expanded newborn screening: Review and update. Crit Rev Clin Lab Sci. 2013;50(6):14262.

4. Lee PJ, Lachmann RH. Acute presentations of inherited metabolic disease in adulthood. Clin Med (Lond). 2008;8(6):621-4.

5. Programa Nacional de Diagnóstico Precoce - Relatório 2018 - [cited April14, 2019]. Disponible em: http://www.insa.min-saude.pt/programa-nacional-dediagnostico-precoce-\%E2\%94\%80-relatorio-2018/

6. Saúde - Gabinete do Ministro. Diário da República n. ${ }^{0}$ 35/2008 Despacho n. ${ }^{0}$ 4326/2008., Série II Disponible em: https://dre.pt/web/guest/pesquisa/-I search/3484130/details/normal?.jp=true

7. Saúde - Gabinete do Ministro. Diário da República n. ${ }^{0}$ 50/2016. Despacho nº 3653/2016, Série II. Disponible em: https://dre.pt/home/-/dre/73847696/ details/maximized

8. Sirrs S, Hollak C, Merkel M, Sechi A, Glamuzina E, Janssen MC, et al. The Frequencies of Different Inborn Errors of Metabolism in Adult Metabolic Centres: Report from the SSIEM Adult Metabolic Physicians Group. JIMD Rep. 2016;27:85-91.

9. Sechi A, Fabbro E, Langeveld M, Tullio A, Lachmann R, Mochel F, the SSIEM Adult Physicians Metabolic Group. Education and training in adult metabolic medicine: Results of an international survey JIMD Rep. 2019; 49:63-69

10. Direção Geral de Saúde. Abordagem Diagnóstica e Critérios de Referenciação de Doenças Hereditárias do Metabolismo em Idade Pediátrica e no Adulto. Norma da DGS 012/ 2017. [cited April14, 2019]. Disponible em: https://www.dgs.pt/ directrizes-da-dgs/normas-e-circulares-normativas/norma-n-0122017-de12072017-pdf.aspx

11. Direção Geral de Saúde. Cartão da Pessoa com Doença Rara (CPDR). Noma DGS 001/2018 [cited December09, 2018]. Disponible em: https://www.dgs. pt/directrizes-da-dgs/normas-e-circulares-normativas/norma-n-0012018-de09012018-pdf.aspx

12. Ministério da Saúde. Direção-Geral da Saúde. Informação de apoio à pessoa com doença rara 2019, DGS July 2018. [cited June18, 2020]. Disponible em: https:// www.spp.pt/UserFiles/file/Seccoes_Reumatologia/Informacao-de-Apoio-aPessoa-com-Doenca-Rara.pdf

13. Autoridade Nacional do medicamento e produtos de saúde. Monitorizaçao de consumo de medicamentos em meio hospitalar, Infarmed. [cited October, 2019]. Disponible em: https://www.infarmed.pt/documents/15786/3082402/ outubro/426b611a-6a60-6421-1936-452a664e7e70?version=1.0

14. Leão Teles E, Oliveira A, Pereira C, Martins E, Duarte H, Rodrigues J, et al.Comissão Coordenadora do Tratamento das Doenças Lisossomais de Sobrecarga. Relatório de atividades 2018. Instituto Nacional de Saúde Doutor Ricardo Jorge (INSA, IP) [cited January, 2020]. Disponible em: http://www.insa min-saude.pt/wp-content/uploads/2020/02/RelatorioCCTDLS2018.pdf

15. Georgianne $L A$. Inborn errors of metabolism in the 21stcentury: past to present. Ann Transl Med 2018;6(24):467 